\title{
MECHANICAL PRORERTIES OF EXPOSED COLUMN BASE CONNECTIONS FOR L- SHAPED COLUMNS FABRICATED USING CONCRETE-FILLED STEEL TUBES
}

\author{
Jing $\mathrm{Su}^{2}$, Ting Zhou ${ }^{1,2,{ }^{*}}$, Zhi-Hua Chen ${ }^{1,2}$ and Xiao-Dun Wang ${ }^{1,2}$ \\ ${ }^{1}$ Key Laboratory of Coast Civil Structure Safety of China Ministry of Education, \\ Tianjin University, Tianjin, China \\ ${ }^{2}$ School of Civil Engineering, Tianjin University, Tianjin 300072, China \\ "(Corresponding author: E-mail: zhouting1126@126.com)
}

\section{A B S T RA C T}

The response of exposed column base connections for L-shaped column is investigated through finite element analysis (FEA) in this paper which is affected by complex interactions among different components. Three finite element models are constructed to simulate the response of these connections under axial and cyclic horizontal loading, which interrogat e a range of variables including anchor rod strength, base plate size and thickness. The results of the simulations provide insig hts into internal stress distributions which have not been measured directly through experiments. The key findings indicate that thicker base plates tend to shift the stresses to the toe of the base plate, while thinner plates concentrate the stresses under the column flange. Base on the analytical results, a hysteretic model is proposed to describe the cyclic moment-rotation response of exposed column base connections. The core parameters used to define the backbone curve of the hysteretic model are calibrated through configurational details. The comparison between the simulation and the calculated values indicates that the hysteretic model is suitable to characterize the key aspects of the physical response, including pinching, recentering and flag-shaped hysteresis phenomenon. Limitations of the model are outlined.
A R T I CLE H IS TORY

$\begin{array}{ll}\text { Received: } & 9 \text { July } 2020 \\ \text { Revised: } & \text { 15 April } 2021 \\ \text { Accepted: } & \text { 18 April } 2021\end{array}$

\section{K E Y W O R D S}

L-shaped columns;

Finite element analysis;

Exposed column base;

Hysteretic model;

Flexural strength

\section{Introduction}

Column bases are one of the most important components in a real building. Their rotational stiffness and moment resistance affect storey drifts, force distributions and collapse resistance of the whole structure. It is of great importance to design the column bases with sufficient strength, stiffness, as well as energy dissipation capacity. It has been summarized that generally there are three types of column bases in engineering practices, including exposed column bases, embedded column bases and concrete-encased column bases. The exposed type, advancing in fast and easy construction, consists of column, base plate, anchor rods and concrete foundation which bears loads through interactions among various components. The concrete-encased connection can be regarded as an enhanced version of the exposed one, as it is encased by an outer reinforced concrete part on the basis of the base-plate joints. It is not suitable for the large-scale columns with an additional part which could waste much available area. Although the embedded column base inserted into the foundation could achieve higher strength and stiffness compared with the former two, it would increase construction difficulties once the size of the column becomes extremely large that requires very deep embedment.

In recent studies, the concrete-filled special-shaped steel tubular columns (SCFT) have been widely used for its mechanical benefits, such as high strength, superior ductility and high energy-absorption capacity [1]. The width of monocolumn is always smaller than the thickness of the wall, allowing SCFST columns to be embedded into the wall, which provides greater flexibility for architectural design. Three types of SCFST columns have been proposed. Chen et al. [2] proposed a kind of composite special-shaped column, including three cross sections: L-shaped, T-shaped and crisscross-shaped, which are fabricated with mono-rectangular columns and shear connectors. The connectors have developed from the early welded lacing bars [2] to single steel plates [3], and then double steel plates [4]. The second type is the multiple-cell special-shaped concrete-filled steel tubular columns, formed by the connection of multiple rectangular steel tubes through vertical welds. The third one is concrete-filled specialshaped steel tubular column. Compared with the other two types, the composite concrete filled steel tube mono-columns improve the confinement effect of the core concrete. In general, an L-shaped column (L-CFST) composed of three small-sized mono-columns and double steel plate connectors can meet universal demands for structures. It has been studied under axial, biaxial and cyclic loads in past 10 years through experiments and finite element model (FEM) analysis [2-8]. The seismic performance of such structural system constructed with SCFT columns and different lateral resistance members has also been investigated [9-10]. Nevertheless, the number of theoretical works and experimental programs specifically devoted to investigating the seismic behaviors of the SCFT column base connections is limited and the knowledge of them is still far from a complete understanding. As mentioned earlier, the encased connection which could achieve the required strength and stiffness in most situations would meet construction difficulties caused by the large-scale section of the L-CFST column. The exposed connection, relatively simple for construction, which has excellent ductility and large deformation capacity shows good potential for applications in such case. Previous studies [11-22] mainly investigate the major axis bending conditions of the H-section or box section steel column bases, while none examines the response of L-CFST column bases. The strength characterization methods presented in prior researches [17-18] are not applicable to such connections because of the inner anchor bolt layouts and special-shaped base plate. These different configurations alter internal stress distributions and affect the deformation form of the connection that could not be measured directly through experiments. Considering the fact that the seismic performance of exposed L-CFST column bases is influenced by many variables, such as the value of axial load, different loading history, embedment depth and layouts of anchor rods, base plate size and thickness, and experimental tests could consume much accurately interrogating all these parameters, finite element simulations are ideal methods for investigating the connection response. Motivated by these issues, this paper established three finite element (FE) models to observe the response of the L-CFST column base connections. The FE models are highly sophisticated, considering large deformation, complicated contact relations and multi-axial constitutive response of materials. Next section provides a brief overview of the exposed column base studies. Previous study [24] is used as the validation bed of the simulation. Based on the analytical results, a simplified method is proposed to calculate the flexural bearing capacity of the base joints And then a hysteretic model describing the seismic response of the L-CFST exposed connection is developed. Conclusions and limitations are outlined at last.

\section{Background}

Numerous experimental and analytical works have been conducted on exposed base connections to describe their strength, stiffness and failure modes. Unfortunately, the technical literatures devoted to investigating their cyclic response are not as broad as for the beam-to-column joints. It can be explained that the complicated interactions increase the difficulties in establishing an accurate and universal method to characterize the base connection response. Previous experimental studies [11-12] have sought to evaluate the influence of different parameters on their mechanical properties. These findings contributed to the development of the calculation methods in strength and stiffness. Subsequent 
works [13-15] led to a refinement of these methods, but they were not convenient to apply owing to the complicated iterative procedures. Then, new design methods, relying on simplified assumptions, were used in design. These methods assumed that the stress distribution under the base plate contained two categories, namely strain compatibility and strength independence. The calculation results based on these methods showed overall agreement with experimental data. However, such design methods are limited to be generalized considering the indeterminacy of internal forces. To address these issues, Kanvinde et al. [18] examined the physical response and stress distributions of the exposed connections through finite element analysis. Based on the simulation results, the author provided modifications with regard to the plate thickness in strength calculation. And then, a hysteretic model characterizing the connection performance under seismic loading conditions in [21] was proposed.

Looking in literature, prevalent researches [17-21] have devoted to extending the component method mainly applicable for $\mathrm{H}$-section steel column bases. Thus, the derivations are not suitable for L-CFST column base design. Considering the difficulties in measuring them directly through experiments, the finite element simulation method discussed in the following sections is more appropriate to exam the internal force distributions and investigate the connection response.

\section{Finite element analysis (FEA) mode}

As mentioned above, there are complicated interactions at the base plate joints. The model contains highly complex contact relations (between base plates and foundations; between base plates and washers; between nuts and washers; between anchor rods and various hole walls), adding the difficulties in simulating these surface properties. Three FEA models were established to study the seismic behaviors of the exposed L-CFST column bases, shown in Fig. 1. Detailed information of the models is listed in Table1.

\subsection{Elements, interactions, and boundary conditions}

The models are primarily formed by hexahedral(C3D8R) elements, except for the reinforcements using space truss elements. As the deformation mainly concentrates at the base plate joints, anchor bolts are modeled by solid elements to better observe their deformation capacities.

Table 1

Details of models

\begin{tabular}{cccc}
\hline \multirow{2}{*}{ Specimen } & Column & Anchor bolt & Base plate \\
\cline { 2 - 4 } & $\begin{array}{c}B \times B \times t \\
(m m \times m m \times m m\end{array}$ & $\begin{array}{c}\text { Diameter } \\
(\mathrm{mm})\end{array}$ & $\begin{array}{c}B \times B \times t \\
(\mathrm{~mm} \times \mathrm{mm} \times \mathrm{mm})\end{array}$ \\
\hline ZJ1 & $150 \times 150 \times 10$ & 20 & $650 \times 650 \times 20$ \\
ZJ2 & $150 \times 150 \times 10$ & 20 & $850 \times 850 \times 40$ \\
ZJ3 & $150 \times 150 \times 10$ & 36 & $850 \times 850 \times 40$ \\
\hline
\end{tabular}

The welded connections are simulated as "tie", with the assumption that the welds are detailed enough to resist fracture. The anchor rods and nuts are modeled as monolithic as well to reduce calculation burden, as indicated in [18]. For the interface between the base plate and foundation, contact is defined as surface-to-surface property. The normal behavior is set as "hard contact" and the tangential behavior is simulated through the "Coulomb friction" model according to CECS-230-2008 [23]. The anchor rods are embedded into the foundation considering their embedment depth is enough to resist adhesive damage. The bond relation between steel and concrete in L-CFST column is simulated using the contact element, as stated in [24].The bottom surface of the foundation is fixed. The column base is subjected to axial and cyclic lateral loads controlled by the drift ratio $\theta$, defined as $\theta=\Delta / \mathrm{H}$, where $\Delta$ is the horizontal displacement and $\mathrm{H}$ is the height from the loading point to the foundation surface. The drift ratio $\theta$ is taken as $\pm 0.003 \mathrm{rad}, \pm 0.006 \mathrm{rad}, \pm 0.012 \mathrm{rad}, \pm 0.018 \mathrm{rad}, \pm 0.024 \mathrm{rad}$, and $\pm 0.03 \mathrm{rad}$, increasing gradually with two cycles until the drift ratio is more than $0.1 \mathrm{rad}$

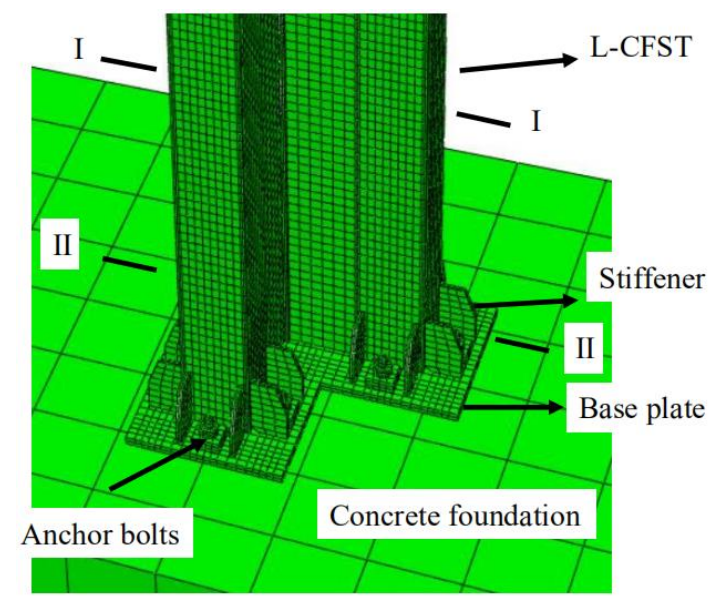

Fig. 1 Overview view of the FEA m

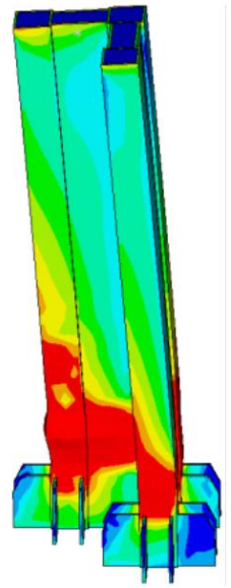

(a) failure mode in [24]

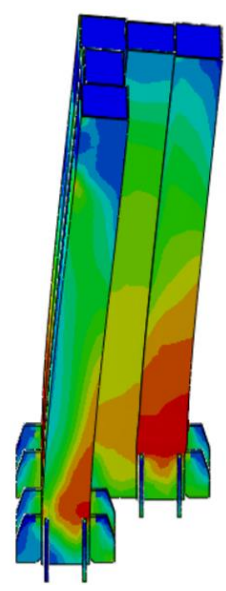

(b) failure mode in this study
Fig. 2 Failure mode of the L-CFST column in [24] and in this study respectively.

\subsection{Constitutive models for concrete and steel}

As stated in Reference [24], the constitutive model of the concrete is described using the incremental theoretical elastic-plastic constitutive model. The steel components are modelled with trilinear curves, while the anchor bolts use the ideal elastoplastic model.

\subsection{Validation of the finite element models}

The experiments conducted previously in [24] are used as a validation testbed. Table 2 shows the key parameters used in these tests. Referring to Table 2, the experiments provide a rich matrix of column sizes enabling the validation against a comprehensive data set. The failure modes are similar, as shown in Fig. 2 , concentrated at the column feet.

Table 2

Details of specimens

\begin{tabular}{ccccccc}
\hline Specimen & $\mathrm{L}(\mathrm{mm})$ & $\begin{array}{c}\mathrm{B} \times \mathrm{B} \\
(\mathrm{mm} \times \mathrm{mm})\end{array}$ & $\begin{array}{c}\mathrm{D} \\
(\mathrm{mm})\end{array}$ & $\mathrm{n}$ & $\begin{array}{c}t_{1} \\
(\mathrm{~mm})\end{array}$ & $\begin{array}{c}t_{2} \\
(\mathrm{~mm})\end{array}$ \\
\hline SJ1 & 1500 & $100 \times 100$ & 150 & 0.4 & 4 & 4 \\
SJ3 & 1500 & $150 \times 150$ & 150 & 0.4 & 4 & 4 \\
SJ4 & 1500 & $100 \times 100$ & 100 & 0.4 & 4 & 4 \\
\hline
\end{tabular}

$\mathrm{L}$ represents the length of the column. $\mathrm{B}$ is the width of the steel tube. $\mathrm{D}$ is the width of the steel plate. $\mathrm{n}$ is the axial compression ratio. $t_{1}$ and $t_{2}$ is the thickness of the steel tube and steel plate respectively.

The comparisons between the skeleton curves of the FEM analysis and the experiments are shown in Fig. 3. Small differences between the results of tests and simulations are observed. The errors possibly can be caused by some factors: 1) the gap between the concrete and steel tubes in actual working conditions, 2) the damage of concrete is underestimated, 3) the heterogeneity of the materials and initial defects in specimens. Nevertheless, as the predictions generally match with the experiments well, it could be concluded that the FEA models are suitable for further analysis. 


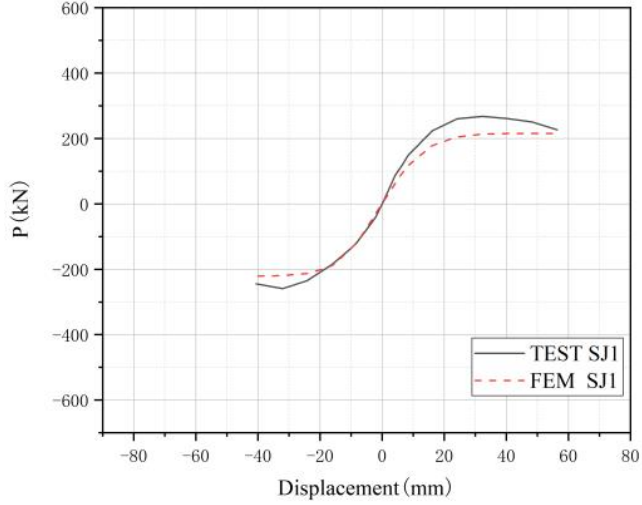

(a) Skeleton curves of SJ-1.

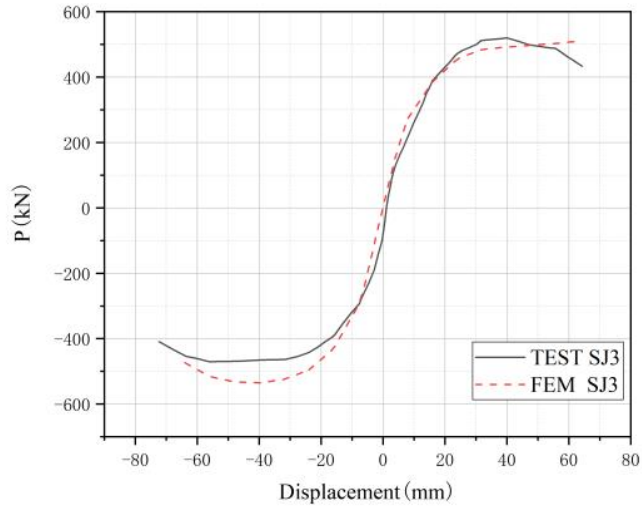

(b) Skeleton curves of SJ-3.

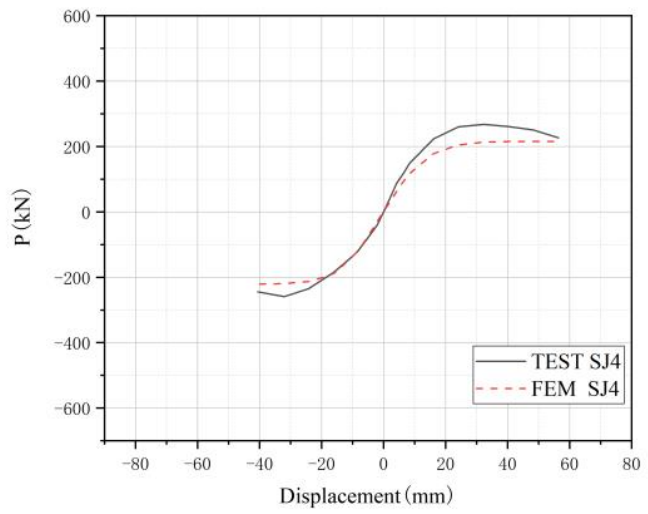

(c) Skeleton curves of SJ-4.

Fig. 3 Comparison between the skeleton curves of the FEM and test.

\section{Analytical investigation}

Three FE models were constructed and analyzed. Referring to Table 1, variables mainly include the base plate size and thickness, diameter of the anchor rods to investigate the influence of different parameters on seismic performance of the exposed base connections.

\subsection{Internal stress distributions}

The FE models provide an opportunity to examine internal stress distributions in the base connection. Fig. 4 illustrates the concrete stress distributions in the plane of the moment, assuming that stress within the width of the plate is invariant. It can be seen that the stress mainly concentrates on the flange of the column for ZJ1, while that shifts to the edge of the ribs for $\mathrm{ZJ} 2$ and $\mathrm{ZJ} 3$, caused by the differences in the plate thickness, as summarized in [18].

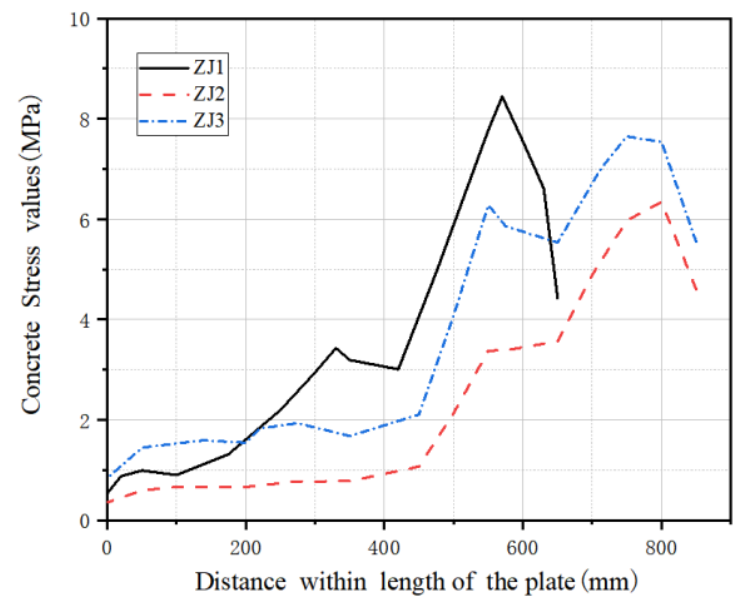

Fig. 4 Stress distribution under the base plate.

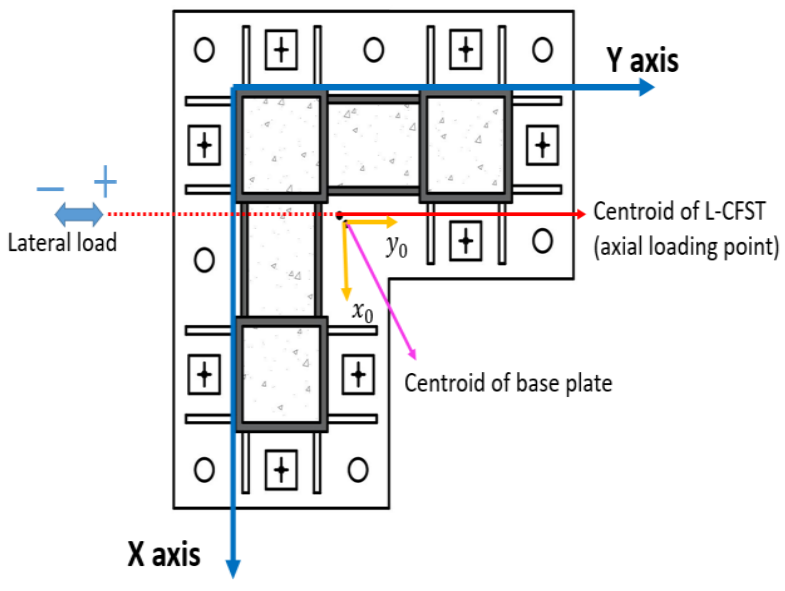

Fig. 5 Definition of the bottom section and loading directions.

\subsection{Failure modes and strength}

Previous experimental and analytical studies [11-22] have indicated that the exposed connections are prone to fail at the base plate joints, such as plastic elongation of anchor rods, yield of the base plate and spalling of concrete. Table 3 shows the drift ratio $\theta$ for each failure mode. The definition of the bottom section is shown in Fig. 5, marking out the positive and negative loading directions. The damage began with the anchor bolts for all three models, indicating that the anchor bolts were weaker than the base plate, such that simply increasing the size of the base plate did not significantly delay the initial yield phenomenon. The anchor bolts of ZJ2 and those of ZJ1 began to yield at the same degree of bending effect, while those of ZJ3 failed later owing to its larger diameter. Then the second-yield event occurred on the base plate. Table 3 shows that the thicker base plate has higher strength and provides more resistance after the anchor bolts yield. 
Table 3

Drift ratio of each fracture mode

\begin{tabular}{ccccc}
\hline Specimen & \multicolumn{2}{c}{ Anchor rods yield (rad) } & \multicolumn{2}{c}{ Base plate yield (rad) } \\
\cline { 2 - 5 } & $\begin{array}{c}\text { Positive } \\
\text { direction }\end{array}$ & $\begin{array}{c}\text { Negative } \\
\text { direction }\end{array}$ & $\begin{array}{c}\text { Positive } \\
\text { direction }\end{array}$ & $\begin{array}{c}\text { Negative } \\
\text { direction }\end{array}$ \\
\hline ZJ1 & 0.003 & 0.003 & 0.012 & 0.012 \\
ZJ2 & 0.003 & 0.003 & 0.018 & 0.018 \\
ZJ3 & 0.006 & 0.006 & 0.024 & 0.024 \\
\hline
\end{tabular}

As the deformation increased, concrete under the compression side crushed. It could not be observed directly through the simulation but was associated with the negative slope of the curve, indicating the reduction in stiffness and strength. The maximum lateral resistances shown in Fig. 6 were not equal in two directions because of the asymmetric bottom section. One was attributed to that the loading started from the positive direction and the anchor bolts had accumulated plastic deformation when the lateral load reversed. Another reason was caused by the differences of bearing capacities of the L-CFST column in two directions.

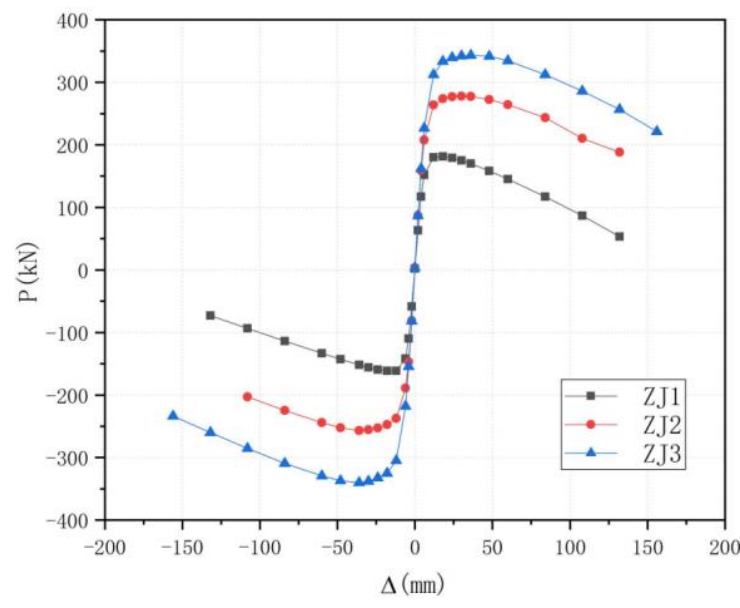

Fig. $6 P-\Delta$ envelop relation of three models.

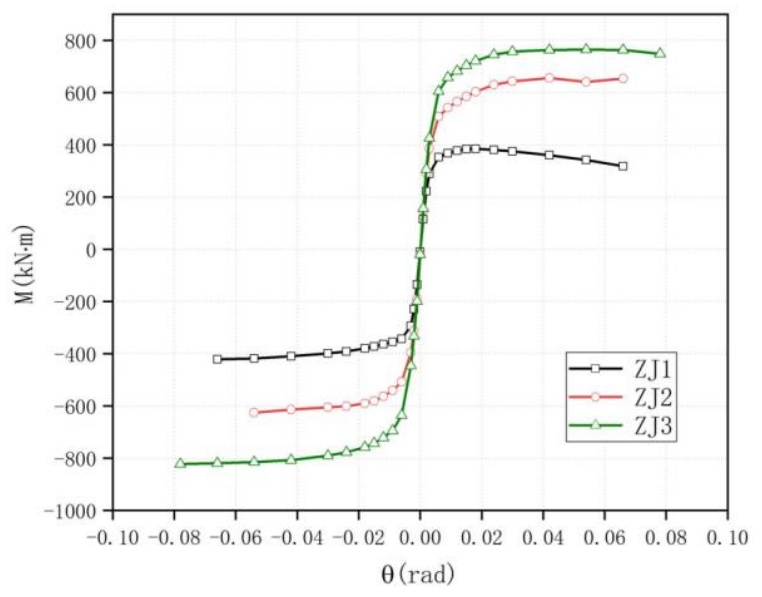

Fig. $7 \mathrm{M}-\theta$ envelop relation of three models.

As mentioned above, the degradation in strength and stiffness is caused by two key events. The moments corresponding to these two events are denoted as $M_{y}$ and $M_{\max }$ which are shown in Fig. 7. Despite the limited ranges of parameters investigated in this simulation, it is stated that the base connections have higher strength with enhanced settings.

\subsection{Strength calculation}

The response of the L-CFST column base connections is the result of nonlinear interactions. Thus, previous approaches [15,18-19] relying on assumed stress distributions under the base plate cannot be applied for this type of connection. The eight-rod configuration and special-shaped base plate increase the degree of static indeterminacy within the connection. The method presented in this section does not characterize the nonlinear interactions in an explicit way but rather devotes to providing a simplified method that can be applied in a practical setting conveniently. During the loading process, the bottom section was subjected to bidirectional bending effect caused by the eccentricity between the centroid of the column section and that of the base plate. The moment of the bottom section can be decided by Eq. (1), and Eq. (2):

$$
\begin{aligned}
& M_{x}=P \times H+N \times\left(y-y_{0}\right) \\
& M_{y}=N \times\left(x-x_{0}\right)
\end{aligned}
$$

Where $P$ is the horizontal load along y-axis; $N$ is the axial load at the top of the column; $x, y$ are the displacement of the loading point along $\mathrm{x}$-axis and $\mathrm{y}$ axis respectively; $x_{0}, y_{0}$ are the coordinates of the centroid of bottom section respectively.

The calculated flexural strength of the column bases, as well as the simulated results are shown in Fig. 8. The agreement between two values demonstrates that the method provides sufficient accuracy, especially in the early loading phase, and the maximum error is less than $10 \%$. According to the regulations in [23] the anchor rods in compression side are not involved in the strength calculation. As shown in Fig. 9, the strain compatibility method proposed in [28] is utilized.

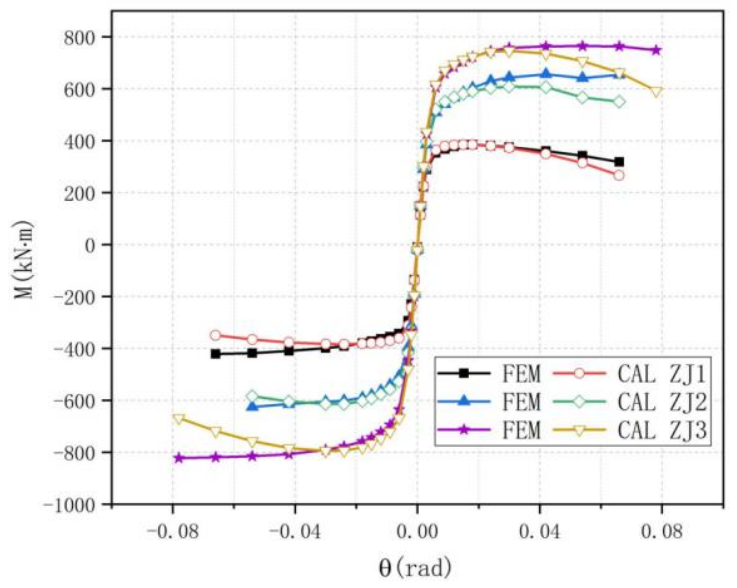

Fig. 8 Comparison between simulations and calculations

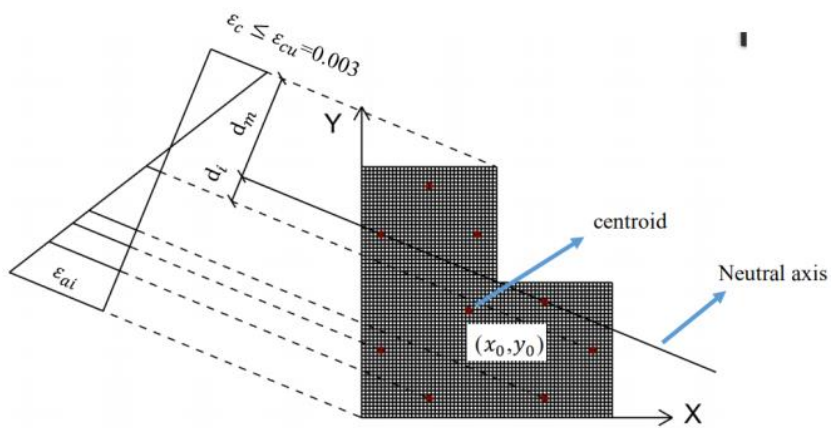

Fig. 9 Strength model for the bottom section.

Following assumptions are used to predict the flexural strength. (1) Linear stain distribution for the bottom section, (2) The extreme strain of concrete in compression side attains $3000 \mu \varepsilon$, (3) The extreme strain of anchor bolts in tension side is equal to $10000 \mu \varepsilon$, (3) The tensile strength of concrete is neglected, (4) The constitutive model of anchor bolts follows the ideal elastic-plastic model, (5) The concrete compression stress-strain relation is defined referring to [27], as outlined in the following equations:

$\sigma_{c}=\left\{\begin{array}{cc}f_{c}\left[\frac{2 \varepsilon}{\varepsilon_{0}}-\left(\frac{\varepsilon}{\varepsilon_{0}}\right)^{n}\right], & \varepsilon<\varepsilon_{0} \\ f_{c}, & \varepsilon_{0} \leq \varepsilon \leq \varepsilon_{c u}\end{array}\right.$

$n=2-\frac{1}{60}\left(f_{c u, k}-50\right)$

$\varepsilon_{0}=0.002+0.5\left(f_{c u, k}-50\right) \times 10^{-5}$

$\varepsilon_{c u}=0.003-0.5\left(f_{c u, k}-50\right) \times 10^{-5}$

$n \leq 2$, if the calculation value is greater than 2 , then $n=2$.

Where $\sigma_{c}$ is the compressive stress of concrete, $f$ is the axial compressive strength of concrete, $\varepsilon_{0}$ is the compressive strain of concrete corresponding to the compressive strength $f_{c}, \varepsilon_{c u}$ is the extreme strain of concrete, $f_{c u, k}$ 
is the concrete cubic compressive strength, $\mathrm{n}$ is a coefficient.

Specific calculation procedures are shown in Fig. 10, as indicated in following steps:

(1) Divide the bottom area into several small rectangular units in which the base plate is located. The coordinates of each small concrete unit and anchor bolts are defined as $\left(x_{c i}, y_{c i}\right),\left(x_{s i}, y_{s i}\right)$ respectively.

(2) A neutral axis is preliminarily assumed, such that the strain of anchor bolts and each small rectangular unit can be decided according to Eq. (7):

$\varepsilon_{i}=\varepsilon_{c u} u \frac{d_{i}}{d_{m}}$

Where $d_{i}$ is the distance from the centroid of each unit to the neutral axis, $d_{m}$ is distance from the edge of the concrete unit in compression side to the neutral axis.

(3) The stress can be obtained using previous stress-strain relation and following equilibrium equations are established:

$N \leq \sum_{i=1}^{n_{c}} A_{c i} \sigma_{c i}+\sum_{j=1}^{n_{s}} A_{s j} \sigma_{s j}$

$M_{x} \leq \sum_{i=1}^{n_{c}} A_{c i} \sigma_{c i\left(y_{c i}-y_{0}\right)}+\sum_{j=1}^{n_{s}} A_{s j} \sigma_{s j}\left(y_{s j}-y_{0}\right)$

$M_{y} \leq \sum_{i=1}^{n_{c}} A_{c i} \sigma_{c i\left(x_{c i}-x_{0}\right)}+\sum_{j=1}^{n_{s}} A_{s j} \sigma_{s j}\left(x_{s j}-x_{0}\right)$

Where $M_{x}, M_{y}$ are the moment in two directions respectively; $n_{c}$ is the number of concrete units in compression side; $n_{s}$ is the number of anchor bolts in tension side; $\sigma_{c i}, A_{c i}$ are the stress and area of the ith concrete unit respectively; $\sigma_{s j}, A_{s j}$ are the stress and area of the ith anchor bolt respectively, $\left(x_{0}, y_{0}\right)$ are the coordinates of the centroid of bottom surface.

The calculated values are collected in Table 4. It indicates that, on average, the strength calculation method predicts the strength with accuracy, such that the average simulated-to-calculated ratio is 1.02 .

Table 4

Comparison between simulations and calculations.

\begin{tabular}{ccccccc}
\hline \multirow{2}{*}{ Specimen } & \multicolumn{2}{c}{$M_{F E A}(\mathrm{kN} \cdot \mathrm{m})$} & \multicolumn{2}{c}{$M_{C A L}(\mathrm{kN} \cdot \mathrm{m})$} & \multicolumn{2}{c}{$M_{F E A} / M_{C A L}$} \\
\cline { 2 - 7 } & positive & negative & positive & negative & positive & negative \\
\hline ZJ1 & 385 & 379 & 391 & 359 & 0.98 & 1.05 \\
ZJ2 & 656 & 613 & 712 & 564 & 0.92 & 1.08 \\
ZJ3 & 764 & 815 & 746 & 764 & 1.02 & 1.06 \\
Mean & & & & & & 1.02 \\
\hline
\end{tabular}

\subsection{Hysteretic Model for Exposed Column Base Connections}

\subsubsection{Physical response of the connection}

The connection response under cyclic loads is shown in Fig. 11. Each incremental deformation process corresponds to a sudden change in the load-deformation curve. These insets describe half of a cycle and subsequent half-cycle is repeated along similar path. In initial loading stage in Fig. 11(a), the resistance mainly consists of stress in compression side under the plate and axial force at the top of the column, in which the anchor rods do not effect. As the deformation increases, the anchor bolts begin to bear loads. The plate is subjected to bending effect caused by the combination of the stress block under the base plate and tension in anchor rods. The end of this stage is signed by the yield of anchor bolts. After that, multiple components gradually yield, creating sudden changes in the load-deformation curves. The end of the second stage in Fig. 11(b) represents the yield of inner bolts and the failure of base plate is shown in Fig. 11(c) in the third end. With more and more components losing bearing capacities, a strength plateau appears at the end of the fourth stage in Fig. 11(d), illustrating the ultimate strength. The top of the base plate maintains contact with the bottom of nuts in initial unloading stage, as illustrated in Fig. 11(e), while that gradually separates from the nuts because of the plastic deformation of anchor rods, accompanied by a nearly constant moment in Fig. 11(f). Then, the base plate continues to move freely until it contacts the concrete again in Fig. 11(g).

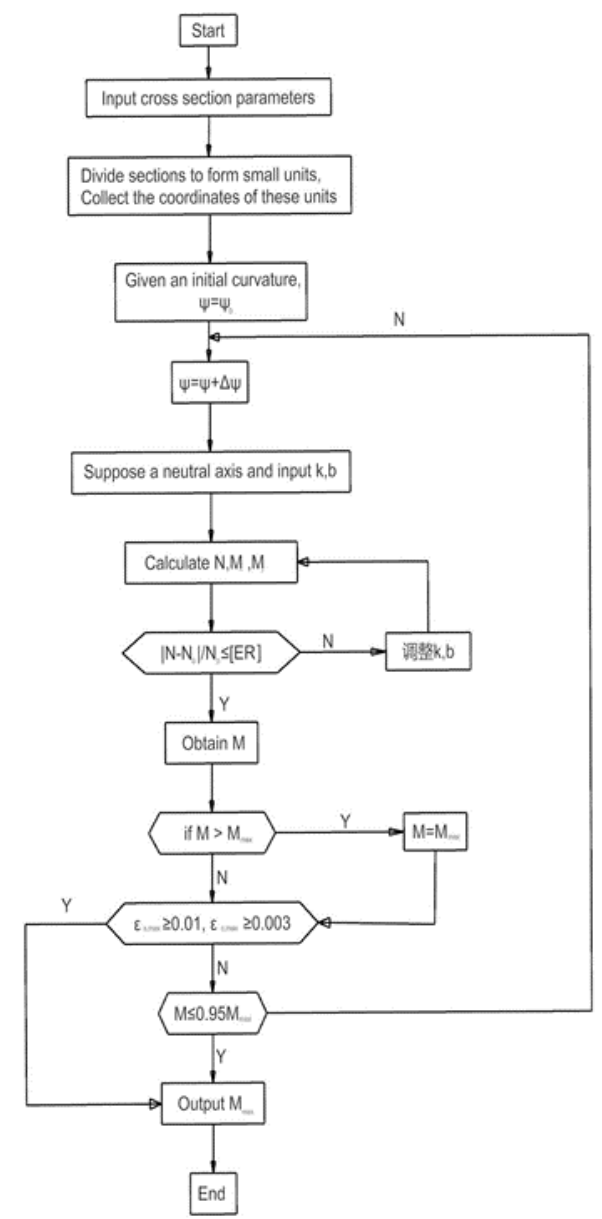

Fig. 10 Flowchart illustrating the proposed method.
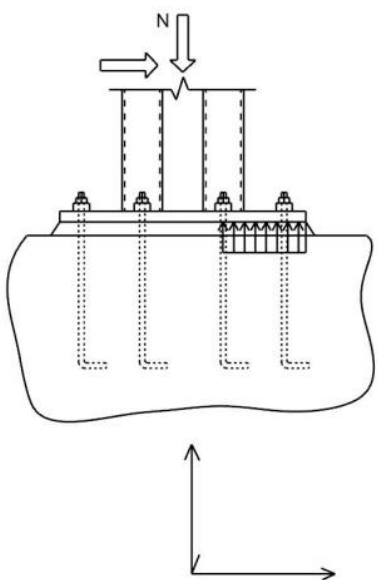

(a)
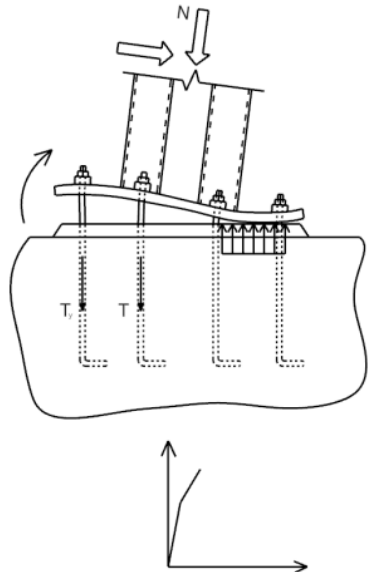

(b)
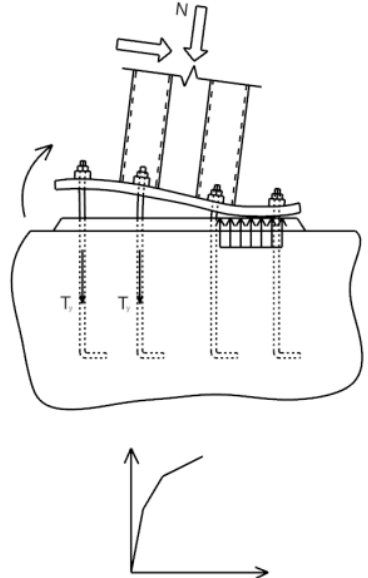

(c)
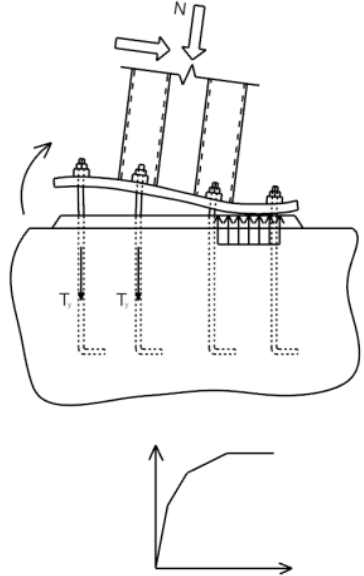

(d) 

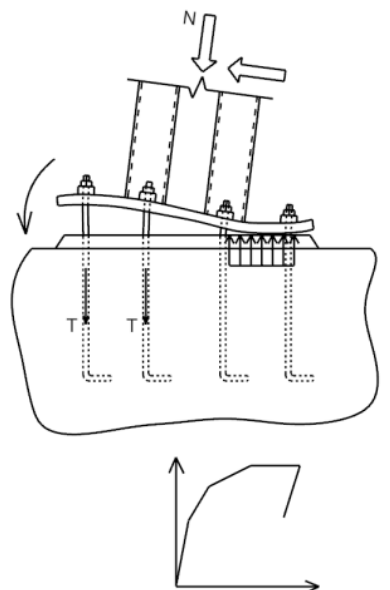

( e )
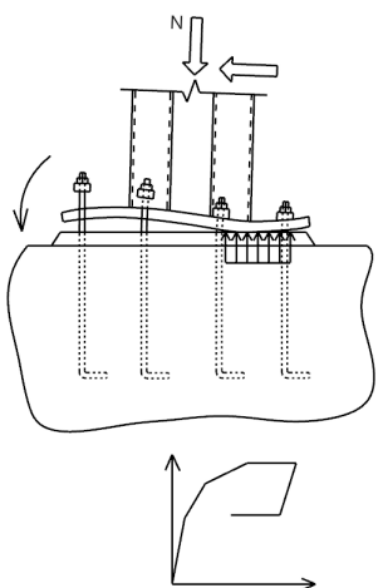

( f)
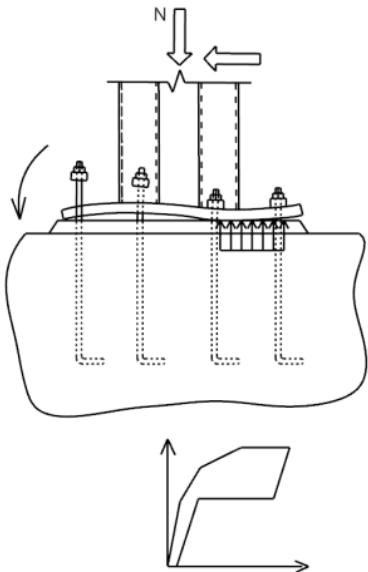

(g)

Fig. 11 Connection response and associated load deformation curves.

\subsubsection{Parameters Defining the Backbone Curve}

The method presented in this section does not characterize the nonlinear interactions explicitly but rather provides a straightforward method that may be applied conveniently in a practical setting. Referring to Fig. 11, the applied moment may be resisted through the bearing stress block under the plate and tension forces in anchor rods. The failure started from the outer anchor rods to the inner rows. Each yield event corresponds to a change in the corresponding moment-rotation curves that are divided into several linear segments.

For example, the backbone curves of $\mathrm{ZJ} 1$ in the positive loading direction consist of five branches. Referring to Fig. 12, the initial elastic Phase I is defined by two parameters including the resistance moment $M_{l}$ and associated rotation $\theta_{l}$. The second branch describes the second-yield event appearing in the end of Phase II. Two additional parameters define this branch, namely $\theta_{2}$ and $M_{2}$. The end of the third branch decided by $M_{3}$ and $\theta_{3}$ means that the yield of the third inner bolt. The strain of concrete in compression side attains $3000 \mu \varepsilon$ before the fourth anchor bolt yields at the end of Phase VI. In Phase V, the backbone curve is described by a horizontal line representing ultimate strength plateau. The manner describing the backbone curve in the negative loading direction resembles similar laws. Each yield event corresponds to a turning point in the curves defined by $M_{i}$ and $\theta_{i}$

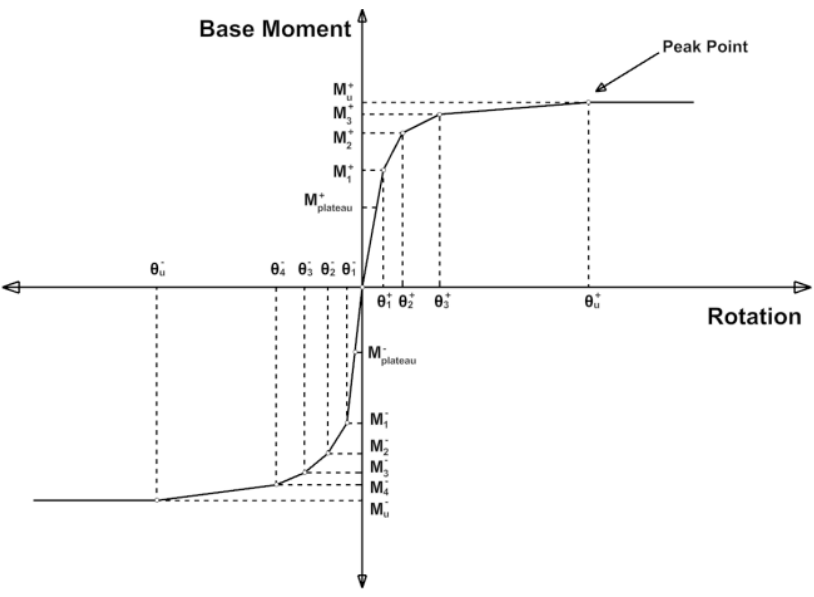

Fig. 12 Parameters defining the backbone curve.

Fig. 13 illustrates the vertical displacement of the base plate under cyclic loading. It can be seen that the part between the anchor bolts approximately satisfy the linear strain assumption. As the deformations of the rods are constrained by the base plate, the linear strain assumption can be extrapolated to the bottom section. Detailed process includes following steps:

(1) Moment of the bottom section.

First it could assume the outermost anchor bolt reached yield and its strain could be obtained using Eq. (11). The strain of other units is decided through the strain compatibility method shown in Fig. 10. In each step, one selected bolt is viewed to be yielding and the strain of concrete units should be proportional to that of the selected yield bolt. Equilibrium equations of the bottom section are outlined in Eq. (8), Eq. (9) and Eq. (10). The key parameter $M_{i}$ of the backbone curve is equal to $M_{x}$ in Eq. (8).

$\varepsilon_{s y}=\frac{\sigma_{y}}{E_{s}}$

$\varepsilon_{s i}=\varepsilon_{s y} \frac{d_{s i}}{d_{y}}$

$\varepsilon_{c i}=\varepsilon_{s y} \frac{d_{c i}}{d_{y}}$

Where $\varepsilon_{s y}, \sigma_{y}$ are the yield strain and stress of the anchor bolt respectively, $E_{s}$ is the elastic modulus of steel, $\varepsilon_{s i}$ is the strain of the bolts in tension side except for the selected yield bolt, $\varepsilon_{c i}$ is the strain of each concrete unit in compression side, $d_{s i}$ is the distance from the centroid line of each anchor rod to the neutral axis, $d_{y}$ is the distance from the centroid line of the selected yield bolt to the neutral axis, $d_{c i}$ is the distance from the centroid of each concrete unit to the neutral axis.

(2) Calculation of the rotation.

The top drift consists of two parts, including the deformation of the L-CFST column and the base plate. The defined parameter $\theta_{i}$ is decided by following equations:

$\Delta_{b o l t}=\frac{\sigma_{y} l_{b}}{E_{s}}$

$\theta_{\text {base }}=\frac{\Delta_{\text {bolt }}}{\left(d_{t}+d_{c}\right)}$

$\theta_{\text {column }}=\frac{M_{i} H}{3 E I_{\text {eff }}}$

$\theta_{i}=\theta_{\text {base }}+\theta_{\text {column }}$

Where $l_{b}$ is the length of the anchor bolt, $\Delta_{b o l t}$ is the elongation of the anchor bolt, $\theta_{\text {base }}$ is the rotation of the bottom section, $d_{t}$ is the distance from the centroid line of the selected yield anchor bolt to the neutral axis, $d_{c}$ is the distance from the center line of the anchor rod in compression side to the neutral axis within the region that satisfies the linear strain assumption, $\theta_{\text {column }}$ is the rotation caused by the deformation of the L-CFST column, $E I_{\text {eff }}$ is the flexural stiffness of the composite section according to [26].

The peak point of the backbone curve is defined by $M_{\max }$ and $\theta_{u}$ based on the proposed strength model and Eq. (18):

$\theta_{u}=\mu \theta_{y}$

Where $\mu$ is the ductility ratio obtained from simulations; $\theta_{y}$ is the yield rotation of the exposed connection. 


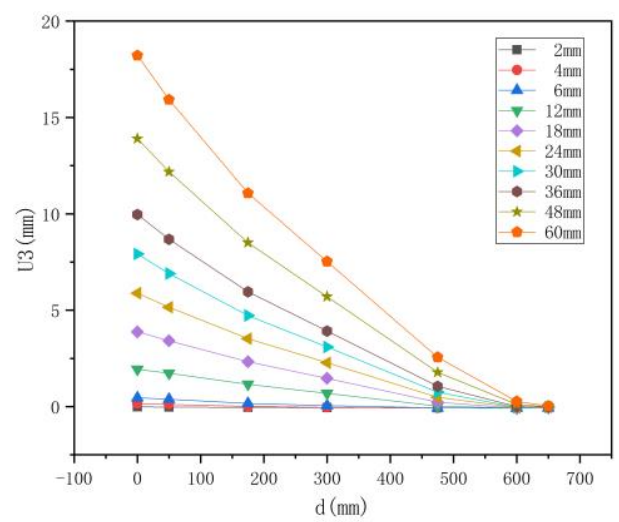

(a) under the positive loading condition

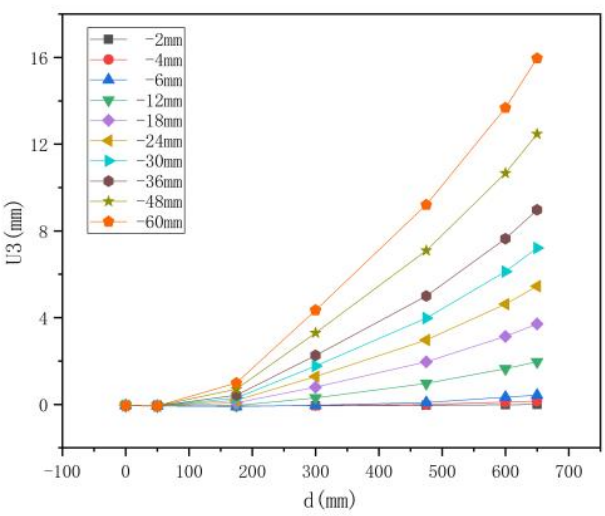

(b) under the negative loading condition Fig. 13 Vertical displacement of the base plate along the edge.
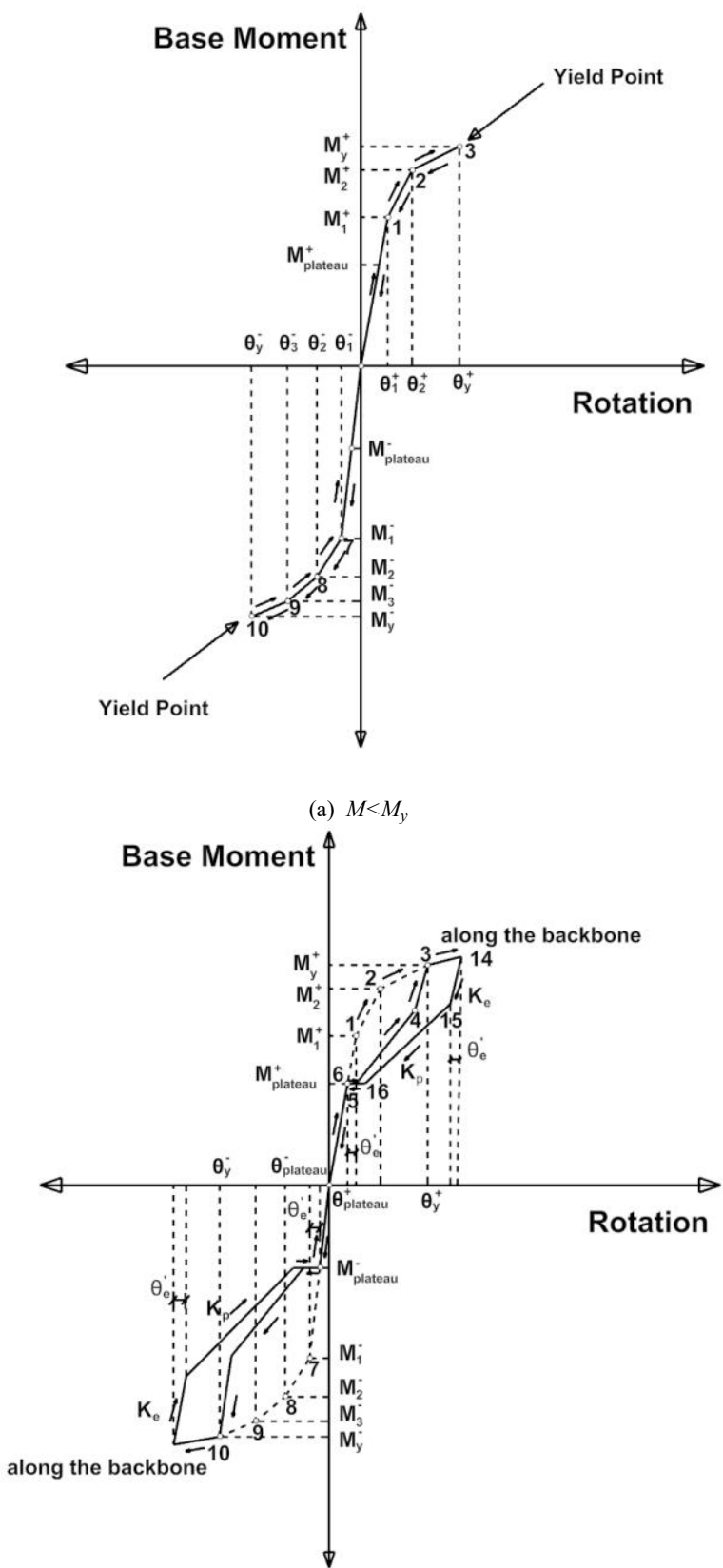

(c) $M_{y}<M<M_{u}$

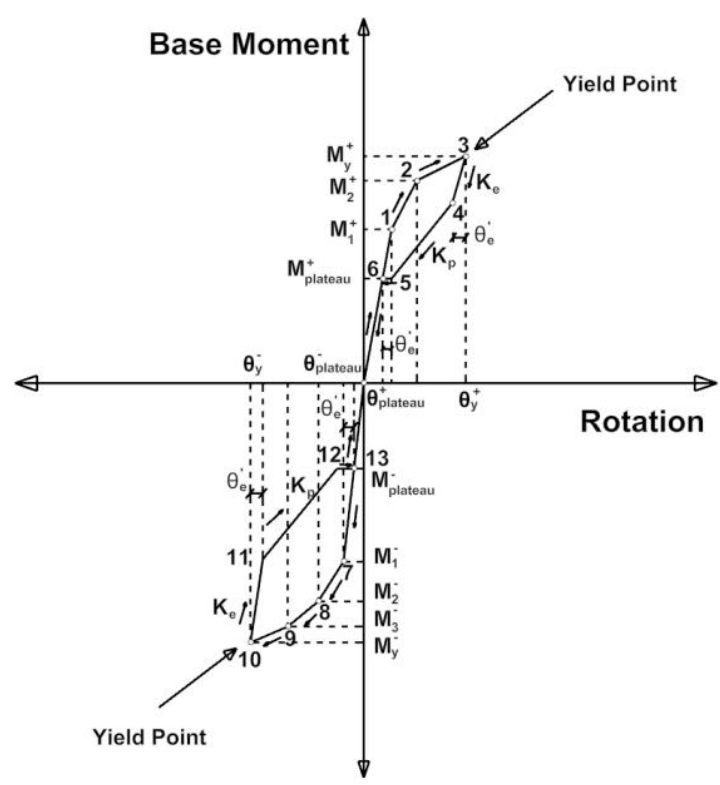

(b) $M_{y}<M<M_{u}$ (initial unloading process)

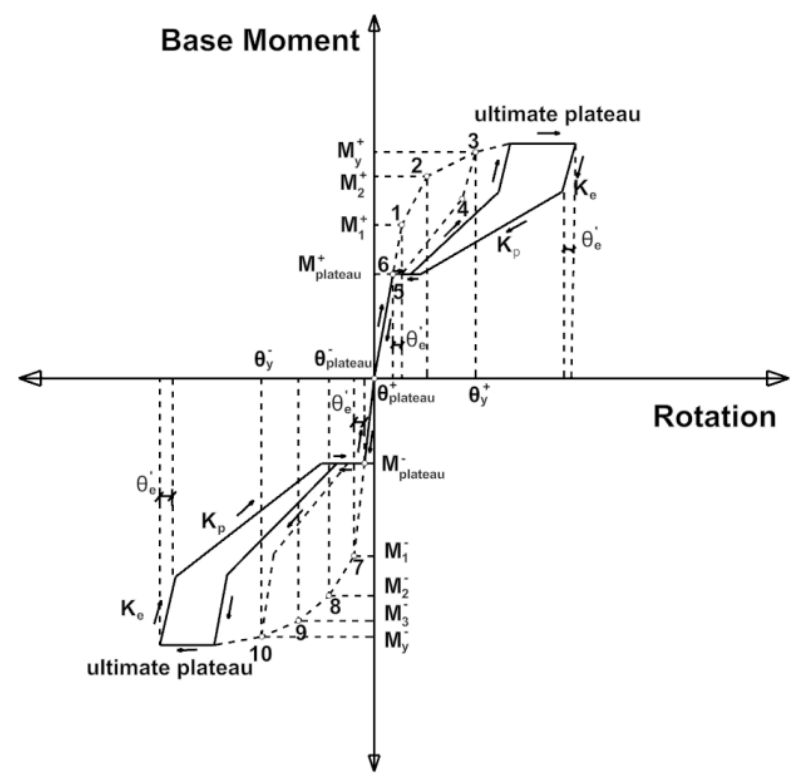

(d) $M>M_{u}$ 


\subsubsection{Rules and Parameters Defining Hysteretic Response}

Fig. 14 illustrates the rules defining the hysteretic response of the exposed connections. Fig. 14(a) shows the initial phase before the yield point. Marker 1 represents the end of Phase I in which the outermost anchor bolt begins to yield. Marker 2 reflects the second-yield event of the inner anchor bolt at the end of phase II. The yield moment of the connection under the positive loading conditions is defined as Marker 3 at the end of Phase III. Unlike the traditional exposed type, connections in this study have inner bolts, such that single yield event cannot represent the yield of the whole. After the former three stages, there is a significant decline in stiffness of the connection. Thus, it is reasonable to regard Marker 3 as the yield point in the positive loading direction. In the same way, Marker 10 in the negative loading condition is defined as the yield point when the fourth anchor bolt begins to yield.

Observing the curves in Fig. 14, the unloading process can be divided into four stages. Stage 1 is the initial elastic unloading process. Stiffness of the first stage, namely $K_{e}$, is equal to the average of phases that the yield point has not occurred. The rotation $\theta_{e}^{\prime}$ in this stage is decided by following equations:

$K_{I}=\frac{M_{I}}{\theta_{1}}$

$K_{I I}=\frac{M_{2}-M_{1}}{\theta_{2}-\theta_{I}}$

$K_{I I I}=\frac{M_{3-} M_{2}}{\theta_{3}-\theta_{2}}$

$K_{e}=1 / 3\left(\left(K_{I}+K_{I I}+K_{I I I}\right)\right.$

$\theta_{\text {plateau }}=\frac{M_{\text {plateau }}}{K_{I}}$

$\theta_{e}^{\prime}=\theta_{1}-\theta_{\text {plateau }}$

Where $K_{I}$ is the initial stiffness of Phase I; $K_{I I}$ is the secant stiffness of Phase II; $K_{I I I}$ is the secant stiffness of Phase III, $K_{e}$ is the elastic unloading stiffness of Stage 1; $\theta_{\text {plateau }}$ is the rotation corresponds to the intermediate plateau; $M_{\text {plateau }}$ is the moment discussed earlier when the anchor bolt has not developed tension force; $\theta_{e}^{\prime}$ is the recoverable rotation in the first unloading stage.

Marker 4 is the end point of this stage decided by $K_{e}$ and $\theta_{e}^{\prime}$. Referring to previous discussions, the pinching phenomenon is caused by cumulated plastic deformation in anchor rods, reflected in Stage 2. The unloading path terminates at Marker 5 containing two parameters $M_{\text {plateau }}$ and $K_{p}$ :

$M_{\text {plateau }}=N \times e$

$K_{p}=\frac{\left(M_{i-} M_{\text {plateau }}\right)}{\left(\theta_{i}-\theta_{\text {plateau }}\right)}$

Where $e$ is the distance from the axial force to the resultant stress line in compression side; $K_{p}$ is the unloading stiffness of the second unloading stage.

From the simulations with regard to stress distributions under the base plate, the definition of $e$ in Eq. (25) is shown in Fig. 15. Owing to the special shape of the base plate, the stress profiles in two directions are different, which are closer to rectangular in the positive direction and triangular in the negative direction. The width of the stress block is equal to the distance from the outermost anchor bolt to the edge of the base plate in the positive loading direction, while that of the negative direction is equal to the distance from the edge of the L-CFST column to the edge of the base plate.

After Maker 5, the moment maintains a constant value called $M_{\text {platea }}$ which corresponds to the free motion of the base plate caused by the separation between the base plate and nuts. The moment in this stage is resisted by the combined effects of the stress block under the base plate and the applied axial load. Marker 6 is the end of this stage. In the fourth unloading stage, the path retraces previous loading path. Further loading and unloading path in the negative direction follows the similar laws described previously from Marker 7 to Marker 13

Fig. 14(b) shows one full scale of loading and unloading process when the moment first reaches the yield point. Subsequent reloading process in the positive direction follows previous unloading path from Marker 6 to Marker 3 and continues along the backbone curve as illustrated in Fig. 14(c). With reference to Fig. 14(d), the model maintains the maximum moment after the connection reaches the limit state with the assumption of no deterioration phenomenon existing within the loading and unloading process.

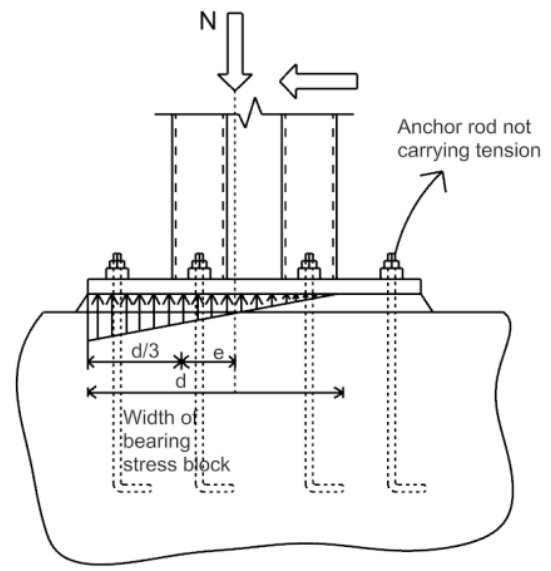

(b) in the negative loading condition

(a) in the positive loading condition

Fig. 15 Illustration of stress distributions used for calculation as Eq. (25).

\subsubsection{Discussion of the results}

Fig. 16 shows the comparison between simulations and calculations using the proposed hysteretic model. It can be seen that the overall response of the connection is well simulated, such that the model may be suitable to characterize the base connection response for which experimental data is not available. The core parameters are determined independently according to configurational details, such that the model is convenient to be generalized into different connection details.

However, there are several inaccurate aspects in the proposed model. First, the simplified hysteretic model does not consider the deterioration from cycle to cycle, such as the strength decline, stiffness degradation and the intermediate plateau decrease, which may be caused by concrete spalling, base plate yield or other damage phenomenon. Second, the unloading path cannot agree well with the simulated results accurately, mainly associated with the methods that are used to determine the parameters of the hysteretic model. Third, the ultimate strength is underestimated, which may be explained by the underestimation of the compressive strength of concrete. 


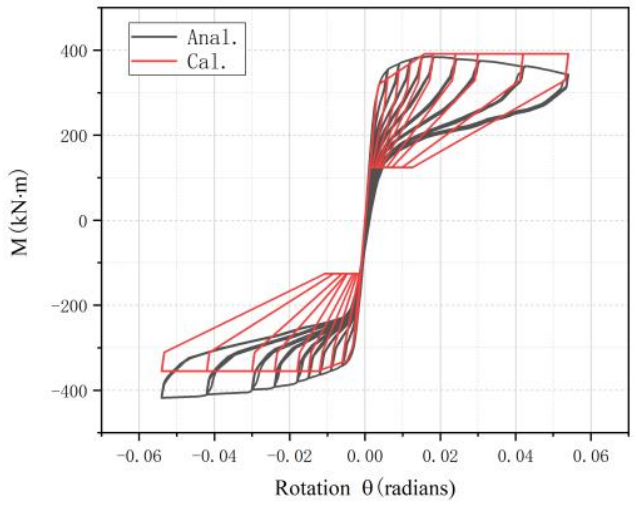

(a) comparison of Model 1

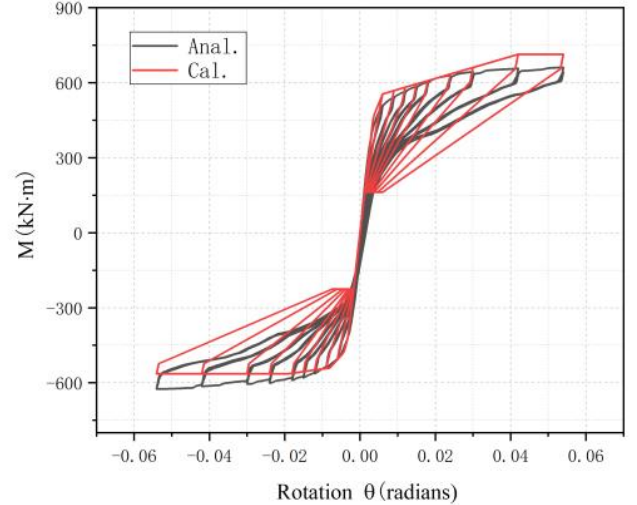

(b) comparison of Model 2

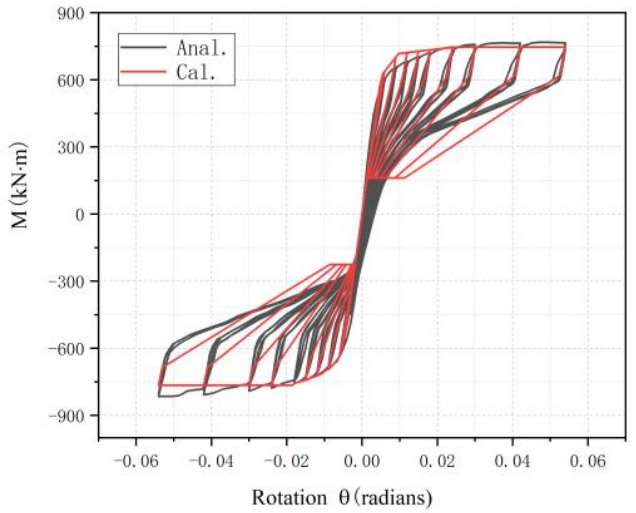

(c) comparison of Model 3

Fig. 16 Comparison between simulations and calculations.

\section{Summary and Conclusions}

The exposed column base connections, investigated in this paper is different from the traditional one owing to its special-shaped base plate and the eightrod anchor bolt layouts, improving the difficulties in describing the mechanic properties of this connection. Current design methods in [23] are mainly applicable to steel column bases. Thus, they are limited to be used in the calculation of L-CFST column base connections. Moreover, these methods are verified only on the basis of overall agreement with test data, while stress distributions and behavioral modes affected by many parameters have not been examined. In additional, there is no explicit design method for such connections in practical settings. To address these issues, the paper established three FE models to simulate the seismic behaviors of the exposed L-CFST column base connections which were verified against previous study [24]. The paper aims to use the simulated results of these connections to investigate the force distributions within the connection and develop an appropriate model for describing their seismic performance. The key finding is that the stress distribution is related to the thickness of the base plate, not simply using the rectangular block in previous assumptions, which can be attributed to the differences in their stiffness. Regardless of the limited parameters investigated in this study, it can be found that the flexural resistance for these connections is improved with enhanced settings.

In this paper, the column base, subjected to cyclic lateral loads, moves in both directions during loading process which leads to a biaxial bending effect on the base plate. Based on the analytical results, a strength calculation method was proposed. The model assumed that the strain distribution under the plate was linear combining features of the "plastic stress distribution method" utilized in [28]. Compared with the simulations, the method could provide reasonable predictions for flexural strength of the connection. And then, the method was

\section{References}

[1] Han, L.H., Li, W. and Bjorhovde, R., "Developments and advanced applications of concretefilled steel tubular (CFST) structures: Members", Journal of Constructional Steel Research, 2014, 100, pp. 211-228.

[2] Chen, Z.H., "New-type special-shaped column by steel structure and composite structure", Steel Construction, 2006, 21(2), pp. 27-29(in Chinese).

[3] Xu, M.Y., Zhou, T., Chen, Z.H., Li, Y.B. L. and Bisby, L., "Experimental study of slender LCFST columns connected by steel linking plates", Journal of Constructional Steel Research, 2016, 127, pp. 231-24 extrapolated to define the backbone curve of the hysteretic model, formed by several linear segments. The core parameters that have the most dominant effect on the hysteretic response can be obtained directly from configurational details, even if no experiment data is available for calibration.

Although the paper has proposed some specific suggestions for the connection design and its inelastic response, it is important to realize the limitations of this study. First, the FE simulation is still fairly limited in terms of the number of parameters studied. Thus, the derivations may not be reliable to connections that are significantly dissimilar to the models in this study. Second, the flexural evaluating method developed in this paper has several limitations that must be considered in its application. For example, the strain distribution assumed to be linear under the base plate is a lack of experimental validation. The current hysteretic model has several limitations, such as its inaccuracy to capture the unloading branch; its inability to incorporate the degradation phenomenon and its ignorance of the discontinuity of the intermediate plateau. Third, the column base models are subjected to a non-proportional loading history, such that the lateral force increases with constant axial load. It cannot represent the seismic loading scenarios. Current hysteretic model represents an appropriate balance between simplicity and accuracy that can be modified by incorporating more parameters. However, it would increase the complexity of the model and limit its generalization.

\section{Acknowledgements}

This research was sponsored by the National Key R\&D Program of China (2019YFD1101005).

[4] Zhang, W., Chen, Z.H. and Xiong, Q.Q., "Performance of L-shaped columns comprising concrete-filled steel tubes under axial compression", Journal of Constructional Steel Research, 2018, 145, pp. 573-590.

[5] Rong, B., Chen, Z.H., Apostolos, F. and Yang, N., "Axial compression behavior and analytical method of L-shaped column composed of concrete-filled square steel tubes", Transactions of Tianjin University, 2012, 18(3), pp. 180-187. 18 (3) (2012) 180-187.

[6] Chen, Z.H., Rong, B., Apostolos, F., "Axial compression stability of a crisscross section column composed of concrete-filled square steel tubes", Journal of Mechanics of Materials and Structures, 2009, (10), pp. 1787-1799.

[7] Zhou, T., Chen, Z.H. and Liu, H.B., "Seismic behavior of special shaped column composed of concrete filled steel tubes", Journal of Constructional Steel Research, 2012, 75, pp. 131- 
141

[8] Chen, Z.H., Zhou, T., and Wang, X.D., "Application of special shaped column composed of concrete-filled steel tubes", Advanced Materials Research, 2011, 163-167, pp. 196-199.

[9] Zhou, T., Jia, Y.M. and Xu, M.Y., "Experimental study on the seismic performance of Lshaped column composed of concrete-filled steel tubes frame structures", Journal of Constructional Steel Research, 2015, 114, pp. 77-88.

[10] Chen, Z.H., Zhao, B.Z., Li, B., Yu, J.H., Yan, X.Y., Wang, D.N. and Zhou, T., "Pushover analysis of special-shaped concrete filled rectangular steel tubular frame-brace system, Industrial Construction, 2017, 47(6), pp. 152-157(in Chinese)

[11] Picard, A. and Beaulieu, D., "Behavior of a simple column base connection", Canadian Journal of Civil Engineering, 1985, 12(1), pp. 126-136.

[12] Thambiratnam, D.P. and Paramasivam, P., "Base plates under axial loads and moments", Journal of Structural Engineering, 1986, 112(5), pp. 1166-1181.

[13] Ermopoulos, J. and Stamatopoulos, G., "Mathematical modeling of column base plate connections", Journal of Constructional Steel Research, 1996, 36, pp. 79-100.

[14] Ermopoulos, J. and Stamatopoulos, G., "Analytical modeling of column base plates under cyclic loading", Journal of Constructional Steel Research, 1996, 40(3), pp. 225-238.

[15] Jaspart, J.P. and Vandegans, D., "Application of the Component Method to Column Bases", Journal of Constructional Steel Research, 1998, 48(2-3), pp. 89-106.

[16] Stamatopoulos, G.N. and Ermopoulos, J.Ch., "Experimental and analytical investigation of steel column bases", Journal of Constructional Steel Research, 2011, 67(9), pp. 1341-1357.

[17] Kanvinde, A.M., Grilli, D.A. and Zareian, F., "Rotational stiffness of exposed column base connections: Experiments and Analytical Models", Journal of Structural Engineering, 2012, 138(5), pp. 549-560.

[18] Kanvinde, A.M., Jordan, S.J. and Cooke, R.J., "Exposed column baseplate connections in moment frames-Simulations and behavioral insights", Journal of Structural Engineering,
2013, 84, pp. 82-93.

[19] Kanvinde, A.M., Higgins, P., Cooke, R.J., Perez, J. and Higgins, J., "Column Base Connections for Hollow Steel Sections: Seismic Performance and Strength Models", Journal of Structural Engineering, 2015, 141(7), pp. 04014171.

[20] Latour, M., Piluso, V. and Rizzano, G., "Rotational behavior of column base plate connections: Experimental analysis and modelling", Engineering Structures, 2014, 68, pp. 14-23.

[21] Rodas, P.T., Zareian, F. and Kanvinde, A., "Hysteretic Model for Exposed Column-Base Connections", Journal of Structural Engineering, 2016, 142(12), pp. 04016137.

[22] Latour, M. and Rizzano, G., "Mechanical modelling of exposed column base plate joints under cyclic loads", Journal of Constructional Steel Research, 2019, 162, pp. 105726.

[23] CECS-230-2008, Specification for Design of Steel-concrete Mixed Structure of Tall Buildings, China Association for Engineering Construction standardization, 2008 (in Chinese)

[24] Xiong, Q.Q., Chen, Z.H., Kang, J.F., Zhou, T. and Zhang, W., "Experimental and finite element study on seismic performance of the L-CFST-D columns", Journal of Constructional Steel Research, 2017, 137, pp. 119-134.

[25] Zareian, F., and Kanvinde, A., "Effect of Column Base Flexibility on the Seismic Response and Safety of Steel Moment Resisting Frames", Earthquake Spectra, 2013, 29(4), pp. 15371559 .

[26] ANSI/AISC 360-05, Specification for Structural Steel Buildings, American Institute of Steel Construction, 2005.

[27] GB 50010-2010, Code for design of concrete structures, China Association for Engineering Construction Standardization, 2010(in Chinese)

[28] Xu, W., Han, L.H. and Li, W., "Seismic performance of concrete-encased column base for hexagonal concrete-filled steel tube: experimental study", Journal of Constructional Steel Research, 2016, 121, pp. 352-369. 